\title{
Do patients with recurrent and de novo metastatic biliary cancer have similar outcomes on treatment?
}

\author{
McNamara $\mathrm{MG}^{1,2 *}$, Aneja $\mathrm{P}^{1}$, Maganti $\mathrm{M}^{3}$, Horgan AM ${ }^{1,4}$, Cleary $\mathrm{SP}^{5}, \mathrm{Knox} \mathrm{JJ}^{\mathbf{1}}$ \\ ${ }^{1}$ Department of Medical Oncology, Princess Margaret Cancer Centre/University of Toronto, 610 University Avenue, Toronto, Ontario, M5G 2M9, \\ Canada. \\ ${ }^{2}$ Department of Medical Oncology, The Christie NHS Foundation Trust, University of Manchester/Institute of Cancer Sciences, Wilmslow Road, \\ Withington, Manchester, M20 4BX, UK. \\ ${ }^{3}$ Department of Biostatistics, Princess Margaret Cancer Centre/University of Toronto, 610 University Avenue, Toronto, Ontario, M5G 2M9, Canada. \\ ${ }^{4}$ Department of Medical Oncology, University Hospital Waterford, Waterford, Ireland. \\ ${ }^{5}$ Department of Surgery, University Health Network, Toronto, Ontario, M5G 2M9, Canada.
}

Received: September 18, 2016; Accepted: October 3, 2016; Published: October 20 , 2016

*Corresponding author: Mairéad G McNamara, Division of Molecular \& Clinical Cancer Sciences, University of Manchester/the Christie NHS Foundation Trust, Wilmslow Road, Manchester M20 4BX, United Kingdom; Tel: +44 (0)161 446 8106; Fax: +44 (0)161 446 $3468 ;$ Email: Mairead.McNamara@ christie.nhs.uk

\begin{abstract}
Background: Biliary tract cancers (BTCs) include cholangiocarcinoma, referring to cancers arising in the intrahepatic perihilar or distal biliary tree, ampulla of vater and gallbladder carcinoma. Even after complete surgical resection, a large number of patients with BTC develop recurrence. Whether recurrence after surgery and de novo metastatic BTC should have comparable stratification in first-line palliative systemic therapy studies is unknown.

Methods: Patients who received palliative chemotherapy as first-line treatment for advanced BTC between January 1987 and May 2014 in Princess Margaret Cancer Centre, Toronto were reviewed. Probability of overall survival (OS) was estimated using the KaplanMeier method, and independent prognostic factors for OS were identified using the multivariable Cox-proportional hazard model.

Results: There were 171 patients with recurrent and 309 with de novo metastatic disease. Median age at diagnosis was 62 years; performance status<2: $436(91 \%)$ patients, male: $262(55 \%)$. In the recurrent group, $102(60 \%)$ had indwelling stents, 33 (32\%) ampulla of vater, 14 (14\%) gallbladder, 55 (54\%) cholangiocarcinoma. In the de novo metastatic group, $173(56 \%)$ had indwelling stents, primary site was ampulla of vater in $13(7 \%)$, gallbladder in $43(25 \%)$, cholangiocarcinoma in 117 (68\%). Systemic treatment received was gemcitabine/platinum doublet in 137 (29\%), gemcitabine/5fluorouracil doublet; 186 (39\%), gemcitabine; 93 (19\%), other; $64(13 \%)$. Median OS for the recurrent group who received firstline palliative chemotherapy was 15.6 months (95\%-confidence interval [CI] 13.5-18.0) and 14.4 months (95\%-CI 12.0-16.0) in the de novo metastatic group. Multivariable analysis for OS revealed that gallbladder as the primary site $(\mathrm{P}=0.04)$ and ECOG performance status $\geq 2(P=0.001)$ were prognostic for worse OS. De novo metastatic status was not prognostic for worse OS compared with recurrent status (Hazard ratio 0.9, 95\% CI-0.66-1.23, $\mathrm{P}=0.51$ ).
\end{abstract}

Conclusions: Similar treatment of patients with recurrent disease after surgery and de novo metastatic BTC, with first-line palliative chemotherapy is acceptable.

Keywords: Biliary tract cancer; Recurrent disease; De novo metastatic; Outcomes

\section{Introduction}

Biliary tract cancers (BTCs) include cholangiocarcinoma, which refers to cancers arising in the intrahepatic, hilar or distal biliary tree, and ampulla of vater and gallbladder carcinoma [1]. These cancers have a poor prognosis with a 5-year survival rate in the range of 5-19\% [2-4]. Complete resection is the only potentially curative treatment, but fewer than $35 \%$ are resectable at presentation and even after complete surgical resection, a large number of patients with BTC develop recurrence $[5,6]$. In a recent retrospective study of 296 patients with BTC who had definitive surgery, 60\% developed recurrent disease [7].

In the $\mathrm{ABC}-02$ study, treatment with cisplatin/gemcitabine was associated with a significant survival advantage over gemcitabine, and so it is the current standard of care for patients with advanced BTC [8]. Whether patients with primary advanced BTC and those with recurrence after surgery should be included in the same category when conducting prospective studies is unknown.

In a retrospective study by Hashimoto et al [9], of 326 patients who received gemcitabine monotherapy as first-line treatment for advanced pancreas cancer, there was no significant difference in survival between recurrent and metastatic disease. It was concluded that it appeared acceptable to treat patients with recurrent pancreatic cancer after surgery and patients with primary metastatic pancreatic cancer similarly.

The aim of this study was thus to investigate whether patients with disease recurrence after surgery and patients with de novo metastatic BTC had similar outcomes on treatment. The results may then provide guidance as to whether comparable first-line palliative systemic therapy or indeed stratification in first-line clinical studies for these two subgroups is appropriate. 


\section{Patients and methods}

The University Health Network database was utilised to identify patients who received palliative systemic therapy as first-line treatment for advanced BTC between January 1987 and May 2014. Institutional review board approval was obtained for this study.

\section{Data collection}

Patient data were collected and analysed retrospectively and included age, gender, Eastern Cooperative Oncology Group performance status (ECOG PS), primary tumour location (gallbladder, intrahepatic, perihilar, distal bile duct and ampulla of vater), staging and tumour histology (adenocarcinoma versus other). Stage classification was based on the pathological findings according to the seventh edition, Tumour Node Metastasis/ American Joint committee on Cancer staging system [10], even for the earliest period in which tumours were retrospectively staged. Staging at initial diagnosis is presented for those with recurrent disease, with all having stage 4 disease on recurrence.

Other details recorded were whether patients had biliary stents in situ or not, receipt of adjuvant treatment in those who had surgery, and palliative treatment received by those diagnosed with advanced BTC. Time to recurrence and overall survival (OS) were recorded in those with recurrent disease and OS was documented for patients with recurrent and de novo metastatic BTC.

\section{Statistics}

Summary statistics were provided for patient demographics. Survival was calculated from the date of recurrence in patients who had previous surgery and from the date of diagnosis in patients with de novo metastatic disease, until date of last follow-up or date of death. The estimates of time to recurrence and OS were calculated using the Kaplan-Meier method. The survival differences between the two groups (recurrent versus de novo metastatic) were examined using the Log-rank test. Univariable and multivariable analysis were performed using the Cox proportional hazard model. Variables included in the multivariable analysis were age, gender, ECOG PS, stage, primary site and whether patients had recurrent or de novo metastatic disease. All tests were two-sided with $\alpha=0.05$. Statistical analyses were performed using the SAS software 9.3 and $\mathrm{R}$ version 3.0.0.

\section{Results}

There were 480 patients who received palliative chemotherapy as first-line treatment for advanced BTC; 171 patients had recurrent disease, 309 had de novo metastatic disease. The baseline demographics for all patients are detailed in Table 1. The median age for all patients was 62 years (range 23-93). The median follow-up time for all alive patients $(\mathrm{N}=90)$ was 16.7 months (range 0.3-117); 18.1 months (0.3-116.9) in patients with recurrent disease $(\mathrm{N}=39)$ and 16.4 months (range 2.8-68.7) in patients with de novo metastatic disease ( $\mathrm{N}=51)$.

In the recurrent group, $102(60 \%)$ had indwelling biliary stents; primary site was ampulla of vater in 33 (32\%), gallbladder in $14(14 \%)$, and cholangiocarcinom in 55 (54\%). In the de novo metastatic group, 173 (56\%) had indwelling stents; primary site was ampulla of vater in 13 (7\%), gallbladder in 43 (25\%), and cholangiocarcinoma in 117 (68\%). There was no difference in stent frequency between the recurrent and de novo metastatic group $(\mathrm{P}=0.16)$.

In the recurrent group, 56 patients (33\%) had previous adjuvant therapy. Further details on regimens utilised in this setting are provided in Table 2. Concurrent chemotherapy/ radiotherapy was administered as per best practice institutional guidelines (radiotherapy 52.5 Gy in 30 fractions over 6 weeks with concurrent gemcitabine $40 \mathrm{mg} / \mathrm{m}^{2}$ twice weekly or 45-54Gy in 1.8 to 2 Gy per fraction with continuous infusion 5 -fluorouracil or capecitabine) [7], as data regarding its role in the adjuvant treatment of patients with BTC is limited [11].

Systemic treatment administered in the advanced setting for all patients was gemcitabine in 19\%, gemcitabine/platinum doublet in 29\%, gemcitabine/5-fluorouracil doublet in 39\%, and "other" in 13\%. The "other" group received 5 -fluorouracil based chemotherapy alone, 5-fluorouracil/platinum combinations or were included in phase I trials. Further details are provided in Table 2.

\section{Survival in patients with recurrent versus de novo metastatic disease}

The median time to recurrence in those patients with recurrent disease was 13.2 months ( $95 \%$ CI 11.5-15.6 months).

Table 1: Patient demographics and tumour characteristics for all patients with advanced biliary tract cancer treated with first-line palliative systemic therapy.

\begin{tabular}{|c|c|c|c|c|}
\hline & Covariate* & $\begin{array}{l}\text { All patients } \\
(\mathrm{N}=480) \\
\mathrm{N}(\%)\end{array}$ & $\begin{array}{l}\text { Recurrent } \\
\text { disease } \\
(\mathrm{N}=171) \\
\mathrm{N}(\%)\end{array}$ & $\begin{array}{l}\text { De novo } \\
\text { metastatic } \\
(\mathrm{N}=309) \\
\mathrm{N}(\%)\end{array}$ \\
\hline Gender & $\begin{array}{l}\text { Female } \\
\text { Male }\end{array}$ & $\begin{array}{l}218(45) \\
262(55)\end{array}$ & $\begin{array}{l}75(44) \\
96(56)\end{array}$ & $\begin{array}{l}143(46) \\
166(54)\end{array}$ \\
\hline Age (years) & $\begin{array}{l}\leq 65 \\
>65\end{array}$ & $\begin{array}{l}298(62) \\
182(38)\end{array}$ & $\begin{array}{l}106(62) \\
65(38)\end{array}$ & $\begin{array}{l}192(62) \\
117(38)\end{array}$ \\
\hline $\begin{array}{l}\text { Primary } \\
\text { tumour } \\
\text { location }\end{array}$ & $\begin{array}{l}\text { Ampulla of vater } \\
\text { Distal bile duct } \\
\text { Gallbladder } \\
\text { Intrahepatic bile } \\
\text { duct } \\
\text { Hilar }\end{array}$ & $\begin{array}{l}66(14) \\
100(21) \\
123(26) \\
106(22) \\
85(18)\end{array}$ & $\begin{array}{l}50(29) \\
43(25) \\
29(17) \\
29(17) \\
20(12)\end{array}$ & $\begin{array}{l}16(5) \\
57(18) \\
94(30) \\
77(25) \\
65(21)\end{array}$ \\
\hline $\begin{array}{l}\text { ECOG } \\
\text { performance } \\
\text { status }\end{array}$ & $\begin{array}{l}0-1 \\
\geq 2 \\
\text { Not available }\end{array}$ & $\begin{array}{l}436(91) \\
27(6) \\
17(4)\end{array}$ & $\begin{array}{l}160(94) \\
4(2) \\
7(4)\end{array}$ & $\begin{array}{l}276(89) \\
23(7) \\
10(3)\end{array}$ \\
\hline $\begin{array}{l}\text { Disease } \\
\text { stage }^{* *}\end{array}$ & \begin{tabular}{|l} 
I \\
II \\
III \\
IV \\
Not available \\
\end{tabular} & $\begin{array}{l}46(10) \\
57(12) \\
28(6) \\
324(67) \\
25(5)\end{array}$ & $\begin{array}{l}46(27) \\
57(33) \\
28(16) \\
19(11) \\
21(12)\end{array}$ & $\begin{array}{l}- \\
- \\
- \\
305(99) \\
4(1)\end{array}$ \\
\hline $\begin{array}{l}\text { Tumour } \\
\text { histology }\end{array}$ & $\begin{array}{l}\text { Adenocarcinoma } \\
\text { Other }\end{array}$ & $\begin{array}{l}439(91) \\
41(9)\end{array}$ & $\begin{array}{l}166(97) \\
5(3)\end{array}$ & $\begin{array}{l}273(88) \\
36(12)\end{array}$ \\
\hline
\end{tabular}

ECOG: Eastern Cooperative Oncology Group. *Due to rounding, all total percentages in Table 1 may not equal 100\%. **Staging at initial diagnosis is presented for the recurrent group. 
The median OS for the recurrent group who received firstline palliative chemotherapy was 15.6 months (95\% CI 13.5-18.0 months) and 14.4 months (95\% CI 12.0-16.0 months) in the de novo metastatic group.

On univariable or multivariable analysis, de novo metastatic status was not prognostic for worse OS compared with recurrent status in those who received palliative chemotherapy (Hazard ratio [HR] $0.89,95 \% \mathrm{CI} 0.72-1.09, \mathrm{P}=0.26$, and $\mathrm{HR} 0.90,95 \% \mathrm{CI}$ $0.66-1.23, \mathrm{P}=0.51$, respectively).

Multivariable analysis for OS revealed that gallbladder as the primary site $(\mathrm{P}=0.04)$ and ECOG performance status $\geq 2(\mathrm{P}=0.001)$ were prognostic for worse OS (Table 3 ).

\section{Discussion}

The majority of patients with de novo metastatic or recurrent disease receiving first-line palliative chemotherapy had ECOG PS $0-1$, and despite potential confounders of prior adjuvant chemotherapy or indwelling stents, once optimised appeared to do equally well. The data supporting the use of adjuvant therapy in BTC is limited but a systematic review and meta-analysis has concluded that patients with lymph node and resection margin positive disease may benefit from this option [12]. In the current study, survival was calculated from the date of recurrence, and there was no difference in the frequency of biliary stenting between the recurrent or de novo metastatic group, and so negating this potential for confounding.

There were more patients included in this study who were $\leq 65$ years but it has recently been reported that OS in elderly patients ( $\geq 70$ years) receiving palliative chemotherapy (monotherapy or combination therapy) are comparable with that of non-elderly

Table 2: Details on systemic therapy received for all patients with advanced biliary tract cancer treated with first-line palliative systemic therapy.

\begin{tabular}{|c|c|c|c|c|}
\hline & Regimen & $\begin{array}{l}\text { All } \\
\text { patients } \\
(\mathrm{N}=480) \\
\mathrm{N}(\%)\end{array}$ & $\begin{array}{l}\text { Recurrent } \\
\text { disease } \\
(\mathrm{N}=171) \\
\mathrm{N}(\%)\end{array}$ & $\begin{array}{l}\text { De novo } \\
\text { metastatic } \\
(\mathrm{N}=309) \\
\mathrm{N}(\%)\end{array}$ \\
\hline $\begin{array}{l}\text { Adjuvant } \\
\text { treatment } \\
(\mathrm{N}=56)\end{array}$ & $\begin{array}{l}\text { Gemcitabine } \\
\text { Concurrent } \\
\text { chemotherapy/ } \\
\text { radiotherapy* } \\
\text { 5-Fluorouracil } \\
\text { Gemcitabine/ } \\
\text { platinum doublet } \\
\text { Gemcitabine/5- } \\
\text { fluorouracil doublet }\end{array}$ & - & $\begin{array}{l}30(54) \\
14(25) \\
\\
8(14) \\
3(5) \\
1(2)\end{array}$ & - \\
\hline $\begin{array}{l}\text { First-line } \\
\text { palliative } \\
\text { systemic } \\
\text { therapy }\end{array}$ & $\begin{array}{l}\text { Gemcitabine } \\
\text { Gemcitabine/ } \\
\text { platinum doublet } \\
\text { Gemcitabine/5- } \\
\text { fluorouracil doublet } \\
\text { Other }^{* *}\end{array}$ & $\begin{array}{l}93(19) \\
137(29) \\
186(39) \\
64(13)\end{array}$ & $\begin{array}{l}44(26) \\
38(22) \\
\\
56(33) \\
33(19)\end{array}$ & $\begin{array}{l}49(16) \\
99(32) \\
130(42) \\
31(10)\end{array}$ \\
\hline
\end{tabular}

Table 3: Univariable and multivariable analysis for overall survival for all patients with advanced biliary tract cancer treated with first-line palliative systemic therapy

\begin{tabular}{|l|l|l|l|}
\hline & Hazard & $\begin{array}{l}\text { Hatio (95\% } \\
\text { Rand Ratio } \\
\text { confidence } \\
\text { interval (CI), } \\
\text { P-value) } \\
\text { (Univariable }\end{array}$ & $\begin{array}{l}\text { (Unterval (CI), } \\
\text { P-value) } \\
\text { (Multivariable } \\
\text { analysis) }\end{array}$ \\
\hline anasis)
\end{tabular}

patients ( $<70$ years) [13], and therefore age should not influence survival in these disease groups.

There was a greater proportion of patients with an ampulla of vater primary in the recurrent disease group than in the de novo metastatic group and is likely reflective of the increased rate of definitive surgery for this primary tumour location (possibly due to earlier presentation with symptoms, for example, jaundice) versus other primary BTC sites, as reported previously [14].

There was no significant difference in OS between patients in the de novo metastatic group versus those in the recurrent group who received palliative chemotherapy. However, the median survival reported for the patients in this study was greater than that in the ABC-02 clinical trial of 11.7 months for those receiving the cisplatin/gemcitabine doublet [8]. The majority of patients 


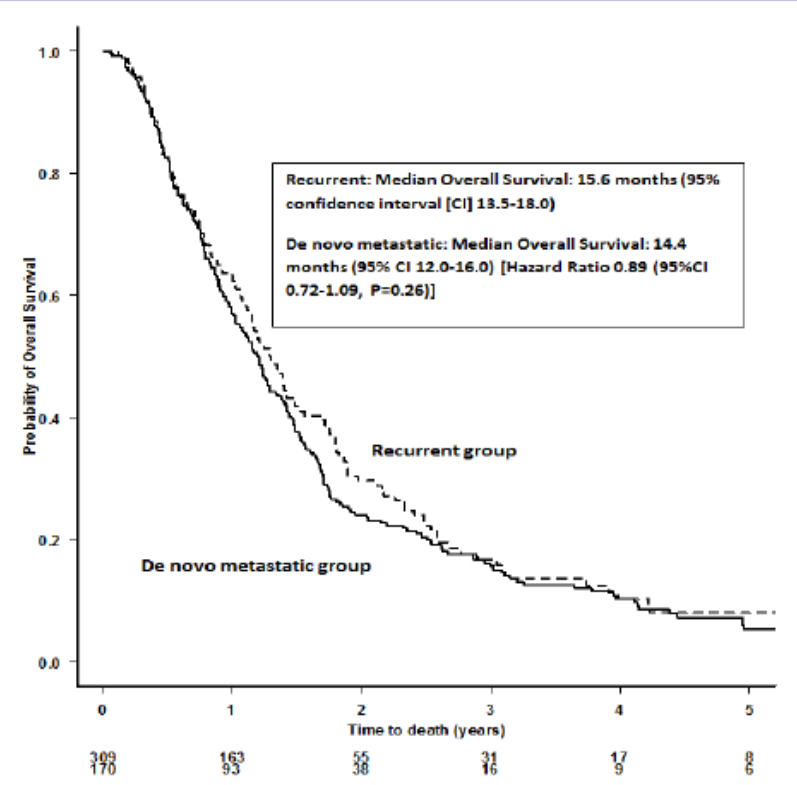

Figure 1: Overall survival in patients with recurrent or de novo metastatic biliary tract cancer

within the current study received either a platinum/gemcitabine [8] or 5-fluorouracil/gemcitabine doublet [15]. In comparison to the ABC-02 study, continuing palliative chemotherapy for longer than eight cycles for those deriving benefit is practiced within Princess Margaret Cancer centre, with treatment breaks for recovery from side-effects [16], and the survival reported is favourable and may be an option for exploration in future prospective studies.

Patients whose primary cancer was situated in the gallbladder or who presented with poor ECOG performance status (PS $\geq 2$ ) were significant independent prognosticators of worse OS. In the randomised phase III trial, ABC-02 [8], the hazard ratio for death in those receiving combination chemotherapy was similar for different primary tumour BTC sites, but comparable to this study, the hazard ratio for death was reduced in those with a better performance status.

The limitations of this study are that this was a single institution retrospective cohort analysis, but it does represent a large series of patients with a diagnosis of BTC treated at a tertiary referral centre and answers a novel question that to the authors knowledge has not been addressed previously.

\section{Conclusion}

Similar treatment of patients with de novo metastatic BTC and recurrent disease with first-line palliative chemotherapy is acceptable and clinical trial stratification is not required for this variable. However, there has been on-going controversy as to whether all anatomic sites of BTC tumour origin should be included in single studies, with proponents of all inclusivity citing the challenges of successful accrual to studies in a rare cancer subtype. Those against inclusivity argue around confounding by lead time bias, heterogeneous rates of complications of biliary obstruction, and perceived differences in prognosis by anatomic site [17]. Indeed, there is emerging evidence suggesting differences in tumour biology by anatomic subtype such as varying rates of driver genomic mutations in genes, such as KRAS, isocitrate dehydrogenase $1 / 2(I D H 1 / 2)$, and fibroblast growth factor receptor 2 (FGFR2) and differences in gene expression associated with extrahepatic versus intrahepatic primary location of the primary tumour [18-20]. Therefore, future rational trial design in this poor prognosis disease may involve stratification by genotype, recruitment to studies enriched for targeted therapies, and identification of novel biomarkers and agents.

\section{Acknowledgements}

Dr Mairéad McNamara was funded by the Princess Margaret Cancer Centre fellowship fund.

\section{Declarations}

There are no conflicts of interest to declare. Institutional review board (Princess Margaret Cancer Centre) approval was obtained for this study.

\section{References}

1. Siegel R, Naishadham D, Jemal A. Cancer statistics, 2013. CA Cancer J Clin. 2013;63(1):11-30. doi: 10.3322/caac.21166.

2. Anderson CD, Pinson CW, Berlin J, Chari RS. Diagnosis and treatment of cholangiocarcinoma. Oncologist. 2004;9(1):43-57.

3. Ben-David MA, Griffith KA, Abu-Isa E, Lawrence TS, Knol J, Zalupski $\mathrm{M}$, et al. External-beam radiotherapy for localized extrahepatic cholangiocarcinoma. Int J Radiat Oncol Biol. 2006;66(3):772-779. doi: 10.1016/j.ijrobp.2006.05.061.

4. Czito BG, Hurwitz HI, Clough RW, Tyler DS, Morse MA, Clary BM, et al. Adjuvant external-beam radiotherapy with concurrent chemotherapy after resection of primary gallbladder carcinoma: A 23-year experience. Int J Radiat Oncol Biol Phys. 2005;62(4):1030-1035. doi: 10.1016/j.ijrobp.2004.12.059.

5. De Groen PC, Gores GJ, LaRusso NF, Gunderson LL, Nagorney DM. N Engl J Med. 1999;341(18):1368-1378. doi: 10.1056/ NEJM199910283411807.

6. Wade TP, Prasad CN, Virgo KS, Johnson FE. Experience with distal bile duct cancers in U.S. Veterans Affairs hospitals: 1987-1991. J Surg Oncol. 1997;64(3):242-245.

7. McNamara MG, Walter T, Horgan AM, Amir E, Cleary S, McKeever EL, et al. Outcome of adjuvant therapy in biliary tract cancers. Am J Clin Oncol. 2015;38(4):382-387. doi: 10.1097/COC.0b013e31829e19fb.

8. Valle J, Wasan H, Palmer DH, David Cunningham, Alan Anthoney, Anthony Maraveyas, et al. Cisplatin plus gemcitabine versus gemcitabine for biliary tract cancer. N Engl J Med. 2010;362(14):12731281. doi: 10.1056/NEJMoa0908721.

9. Hashimoto K, Ueno H, Ikeda M, Kojima Y, Hagihara A, Kondo S, et al. Do recurrent and metastatic pancreatic cancer patients have the same outcomes with gemcitabine treatment? Oncology. 2009;77(3-4):217223. doi: $10.1159 / 000236022$.

10. Edge SB, Compton CC. The American Joint Committee on Cancer: the $7^{\text {th }}$ edition of the AJCC cancer staging manual and the future of TNM. 
Ann Surg Oncol. 2010;17(6):1471-1474. doi: 10.1245/s10434-0100985-4.

11.Ben-Josef E, Guthrie KA, El-Khoueiry AB, Christopher L. Corless, Mark M, et al. SWOG S0809: A phase II intergroup trial of adjuvant capecitabine and gemcitabine followed by radiotherapy and concurrent capecitabine in extrahepatic cholangiocarcinoma and gallbladder carcinoma. J Clin Oncol. 2015;33(24):2617-2622. doi: 10.1200/JCO.2014.60.2219.

12. Horgan AM, Amir E, Walter T, Knox JJ. Adjuvant therapy in the treatment of biliary tract cancer: a systematic review and metaanalysis. J Clin Oncol. 2012;30(16):1934-1940. doi: 10.1200/ JCO.2011.40.5381.

13. McNamara MG, Bridgewater JA, Lopes A, Wasan, H; Malka, D; Jensen, HR; et al. Systemic therapy in elderly patients with advanced biliary tract cancer: sub-analysis of $\mathrm{ABC}-02$ and 10 other prospective studies. J Clin Oncol. 2016.

14. McNamara MG, Horgan A, Walter T, Elizabeth McKeever, Trisha Min, Anne Riga, et al. Biliary tract cancer: A large institutional experience. J Clin Oncol. 2012;30(15):4109.

15. Riechelmann RP, Townsley CA, Chin SN, Gregory R. Pond, Jennifer J. Knox. Expanded phase II trial of gemcitabine and capecitabine for advanced biliary cancer. Cancer. 2007;110(6):1307-1312. doi: 10.1002/cncr.22902

16. Doherty M, McNamara MG, Aneja P, Anne M. Horgan, Raymond WooJun Jang, Neesha C. Dhani, et al. Long-term responders to palliative chemotherapy for advanced biliary tract cancer. J Clin Oncol. 2016;34(4):391.

17. Kelley RK. Biliary tract cancers: finding better ways to lump and split. J Clin Oncol. 2015;33(24):2588-2590. doi: 10.1200/JC0.2015.61.6953.

18. Anderson JB, Spee B, Blechacz BR, Avital I, Komuta M, Barbour A, et al. Genomic and genetic characterization of cholangiocarcinoma identifies therapeutic targets for tyrosine kinase inhibitors. Gastroenterology. 2012;142(4):1021-1031. doi: 10.1053/j.gastro.2011.12.005.

19. Graham RP, Barr Fritcher EG, Pestova E, Schulz J, Sitailo LA, Vasmatzis $\mathrm{G}$, et al. Fibroblast growth factor receptor 2 translocations in intrahepatic cholangiocarcinoma. Hum Pathol. 2014;45(8):16301638. doi: 10.1016/j.humpath.2014.03.014.

20. Borger DR, Tanabe KK, Fan KC, Lopez HU, Fantin VR, Straley KS, et al. Frequent mutation of isocitrate dehydrogenase (IDH)1 and IDh2 in cholangiocarcinoma identified through broad-based tumor genotyping. Oncologist. 2012;17(1):72-79. doi: 10.1634/ theoncologist.2011-0386. 